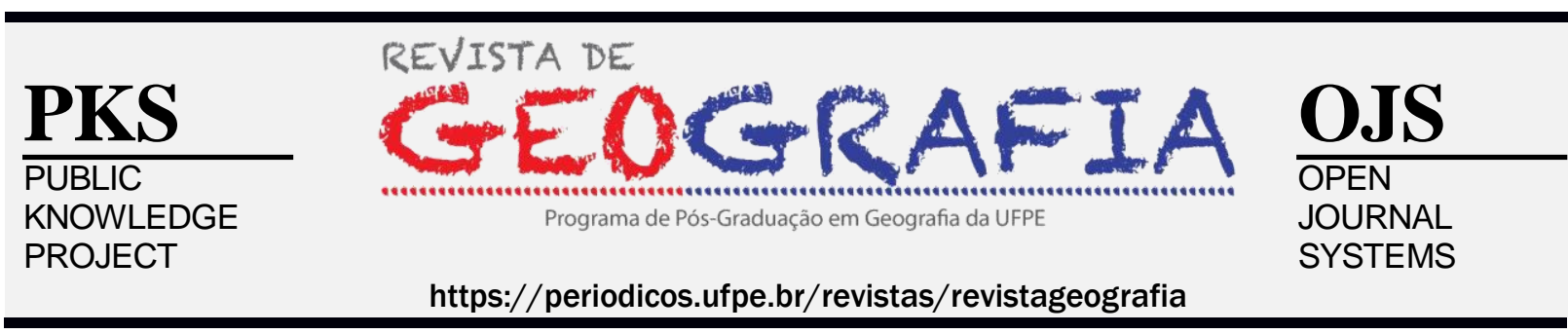

\title{
AVALIAÇÕES DE IMPACTOS NAS IMPLANTAÇÕES DO CULTIVO DO EUCALIPTO NA MESORREGIÃO LESTE DO ESTADO DE ALAGOAS
}

\author{
Verônica Amaral Gurgel ${ }^{1}$, Rochana Campos de Andrade Lima Santos ${ }^{2}$ Karina \\ Ribeiro Salomon ${ }^{3}$
}

\begin{abstract}
${ }^{1}$ Mestre em Geografia pela Universidade Federal de Alagoas. E-mail: veronica.gurgel@gmail.com
${ }^{2}$ Professora doutora do Centro de Tecnologia e do Programa de Pós-graduação em Geografia da Universidade Federal de Alagoas. E-mail: rca.lima@hotmail.com

${ }^{3}$ Professora doutora do Centro de Tecnologia e do Programa de Pós-graduação em Recursos Hídricos e Saneamento da Universidade Federal de Alagoas. E-mail: karina.ctec@gmail.com
\end{abstract}

Artigo recebido em 07/10/2018 e aceito em 02/03/2020

\begin{abstract}
RESUMO
A pesquisa aqui apresentada teve por objetivo analisar a distribuição, ocupação, os impactos econômicos e ambientais da eucaliptocultura nos municípios da Mesorregião do Leste Alagoano em plantio paralelo com a cana-de-açúcar. Com a análise pôde-se evidenciar a importância socioeconômica da Mesorregião, que contém mais da metade dos municípios alagoanos. Com a matriz de impactos, e os valores atribuídos em cada etapa, percebeu-se a geração de diversidades de impactos positivos e negativos. Avaliando-se um total de 84 alterações destacaram-se os impactos: alto negativo (A-) em $25 \%$ dos casos; médio negativo (M-) em $22 \%$; médio positivo $(\mathrm{M}+)$ e baixo negativo (B-) em 13\%; alto positivo (A+) em 12\%; baixo positivo (B+) em $8 \%$ e os impactos nulos ou ausências de alterações em 7\%. Ou seja, grande parte dos impactos gerados foram negativos. Dessa forma, o eucalipto se configura como novo advento socioeconômico e ambiental. Assim, nas áreas já plantadas se faz necessário realizar medidas mitigatórias para o alto e médio impacto negativo. Foi possível perceber assim, que os impactos da eucaliptocultura podem alterar a evolução e a manutenção da exploração deste commodity em anos vindouros.
\end{abstract}

Palavras-chave: Eucalipto; Mesorregião Leste Alagoana; Zona da Mata.

\section{IMPACT ASSESSMENTS IN THE IMPLEMENTATION OF EUCALYPTUS CULTIVATION IN THE EASTERN MESORREGIÃO OF THE STATE OF ALAGOAS}

\begin{abstract}
The research presented here aimed to analyze the distribution of, occupation, economic and environmental impacts of eucalyptus culture in the municipalities of East Alagoas Mesoregion in parallel planting with sugarcane. The analysis showed the socioeconomic importance of the Meso-region, which contains more than half of the municipalities of Alagoas. With the impact matrix, and the values assigned in each step, the generation of diversities of positive and negative impacts was perceived. Evaluating a total of 84 changes, the following were highlighted: high negative (A-) in $25 \%$ of the cases; mean negative (M-) in $22 \%$; mean positive $(\mathrm{M}+)$ and low negative $(\mathrm{B}-)$ in $13 \%$; high positive $(\mathrm{A}+)$ in $12 \%$; low positive $(\mathrm{B}+)$ in $8 \%$ and zero impacts or missing changes in 7\%. In other words, most of the impacts generated were negative. Thus, eucalyptus is configured as a new socioeconomic and environmental advent. Therefore, in areas already planted it is necessary to carry out mitigation measures for high and medium negative impacts. It was possible to see that the impacts of eucalyptus plantations can alter the evolution and maintenance of the exploitation of this commodity in the coming years.
\end{abstract}

Keywords: Eucalyptus; East Alagoas Meso-region; Wood zone. 


\section{INTRODUÇÃO}

Historicamente, a monocultura da cana-de-açúcar foi acompanhada de um quadro de dominação territorial e política, que monopoliza até hoje a economia, o ambiente e a população alagoana. Principalmente no que diz respeito às classes mais vulneráveis da população, que ainda no século XXI não contam com diversificadas oportunidades no mercado de trabalho e são atendidos por políticas públicas com grandes problemas de execução no cumprimento dos direitos sociais.

Para além das dificuldades com a queda do preço de derivados da cana-de-açúcar no mercado, há ainda um advento legislativo que obriga uma iminente paralisação da queima da cana-de-açúcar, dados o parágrafo único do art. 27 da Lei no 4.771, de 15 de setembro de 1965 (código florestal), mediante normas de precaução relativas ao emprego do fogo em práticas agropastoris e florestais (STF, 2013); a Lei Estadual da Queima da Cana (Lei $\mathrm{n}^{\circ}$ 7.454/2013); e mais recentemente, a Portaria do IMA/AL ( $\mathrm{n}^{\circ} 47$ de 05 de outubro de 2015), que trata da queima controlada da cana-de-açúcar.

Sendo assim, desde 2013, de forma efetiva, boa parte dos produtores agrícolas tem implantado a eucaliptocultura como substituição rentável nas áreas de tabuleiro e encostas, porém para esta última ainda não existem maquinários específicos, dificultando assim a colheita da cana-de-açúcar e influenciando a implantação de novos cultivos.

Inicialmente, os plantadores de eucalipto pioneiros de Alagoas realizaram parcerias com a Universidade Federal de Viçosa/MG, que realizou trabalhos de pesquisas quanto a viabilidade e produtividade desse cultivo no estado, implantando 6 áreas de testes distribuídas em municípios diferentes.

Essas modificações com perspectivas de expansão no Estado podem impactar a sociedade, a economia e o meio ambiente, pois ainda são raras as pesquisas específicas sobre essas alterações. A análise aprofundada dos fatores ambientais e socioeconômicos é que poderá vislumbrar e quantificar os pontos positivos e negativos que o advento da eucaliptocultura trará para Alagoas. No entanto, o governo de Alagoas tem apoiado a iniciativa desde o início.

Vale salientar a importância da magnitude das alterações agrícolas atuais no Estado de Alagoas, faz-se necessário também, abordar esse tema por sua importância histórica, econômica e política. Pois as influências dessas decisões destes âmbitos trarão modificações significativas na sociedade, economia e meio ambiente do estado. 
O objetivo desse trabalho foi pesquisar e analisar as transformações das dinâmicas espaciais no Estado de Alagoas com a inserção da eucaliptocultura na Mesorregião do Leste Alagoano em paralelo ou em substituição ao cultivo da cana-deaçúcar, levando às alterações econômicas, ambientais e sociais.

\section{CARACTERIZAÇÃO DA ÁREA DE ESTUDO}

A área do estudo localiza-se no estado brasileiro de Alagoas, mais especificamente denominada de Mesorregião do Leste Alagoano. (Figura 1).

FIGURA 1 - Mapa de localização da área da pesquisa

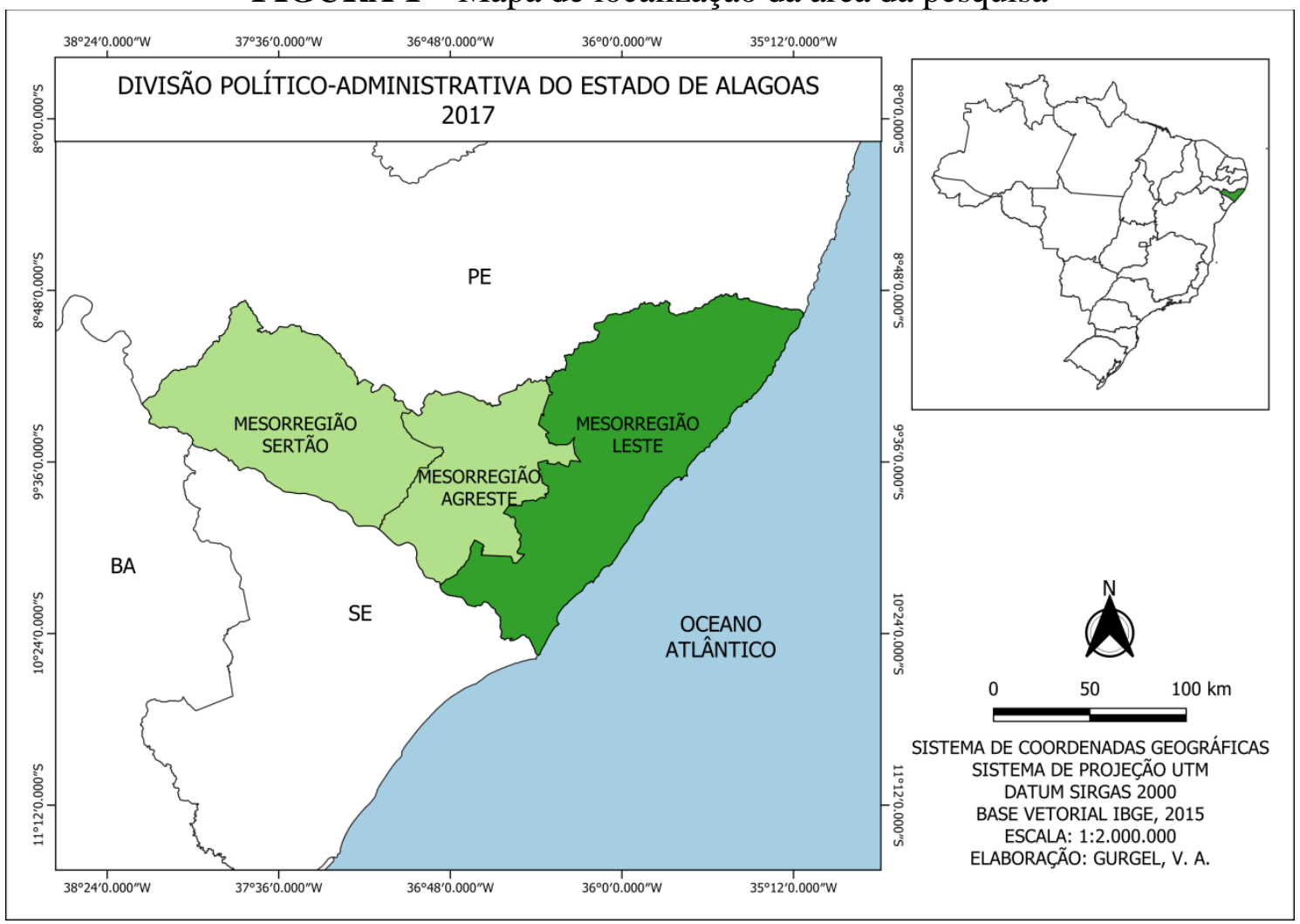

Fonte: IBGE, 2017. Elaboração: GURGEL, V. A. Software livre QGis.

Nesta mesorregião é encontrada a maioria dos plantios de eucalipto do estado. Dos 38 municípios alagoanos com plantio de eucalipto, 33 estão na Mesorregião Leste e 5 na Mesorregião Agreste. (Quadro 1)

Vale salientar que a forma como esses plantios estão distribuídos no estado, evidencia uma maior quantidade dos mesmos na Mesorregião do Leste de Alagoas, justamente onde já se tem estabelecida a monocultura da cana-de-açúcar. 
QUADRO 1 - Distribuição de municípios com plantio de eucalipto por Mesorregião do Estado de Alagoas

\begin{tabular}{|c|l|c|}
\hline Mesorregiões & \multicolumn{1}{|c|}{ Municípios com plantio de eucalipto } & $\begin{array}{c}\text { Quantidade de } \\
\text { municípios }\end{array}$ \\
\hline \multirow{5}{*}{ Leste } & $\begin{array}{l}\text { Atalaia, Anadia, Barra de Santo Antônio, Barra de São Miguel, } \\
\text { Boca da Mata, Campo Alegre, Capela, Cajueiro, Coruripe, } \\
\text { Flexeiras, Igreja Nova, Ibateguara, Jequiá da Praia, Joaquim } \\
\text { Gomes, Japaratinga, Junqueiro, Jacuípe, Matriz de Camaragibe, } \\
\text { Maceió, Murici, Maragogi, Novo Lino, Passo de Camaragibe, } \\
\text { Porto Real do Colégio, Pilar, Porto de Pedras, Paripueira, Penedo, } \\
\text { São Luiz do Quitunde, São Miguel dos Campos, São José da Laje, } \\
\text { Teotônio Vilela, Viçosa. }\end{array}$ & 33 \\
\hline Agreste & $\begin{array}{l}\text { Arapiraca, Feira Grande, Paulo Jacinto, Quebrangulo e Tanque } \\
\text { D'arca. }\end{array}$ & 5 \\
\hline Sertão & & 0 \\
\hline
\end{tabular}

Fonte: Elaborado pelas autoras. Dados: ANGEIRAS, 2016.

Verifica-se que há uma maior quantidade de municípios envolvidos com o plantio de eucalipto na Mesorregião do Leste de Alagoas, bem como, alguns poucos que ultrapassam para a Mesorregião do Agreste. (Figura 2)

FIGURA 2 - Municípios com plantio de eucalipto na Mesorregião Leste do Estado de Alagoas

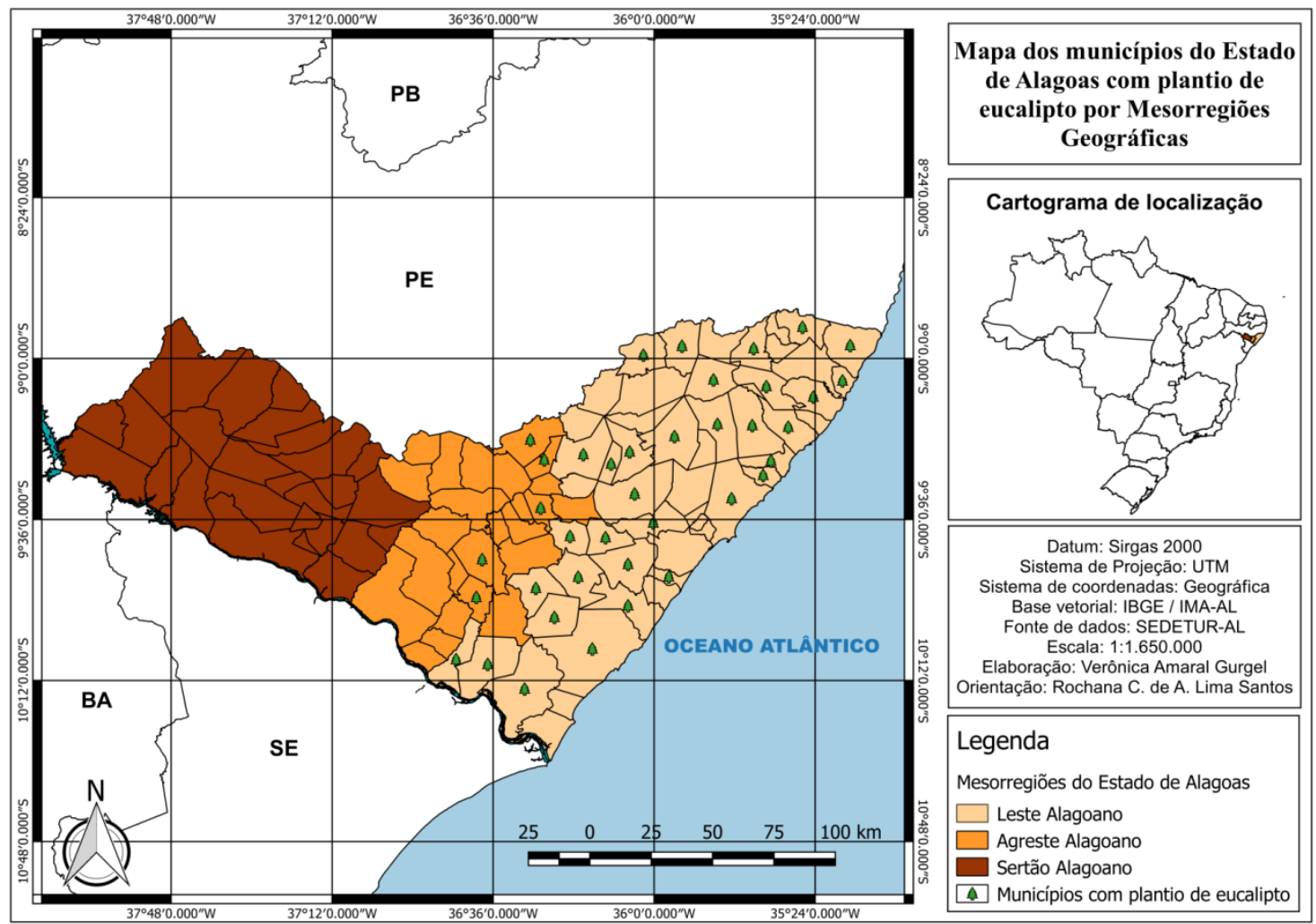

Fonte: GURGEL, V. A., 2018.

Segundo GURGEL (2018, p.71), as regiões hidrográficas dos rios Piaú, Coruripe, São Miguel e Paraíba, que se iniciam na Mesorregião Leste, possuem áreas 
dentro da Mesorregião Agreste, onde se dá justamente a expansão do eucalipto na mesma. Ressalta que a topografia e a geomorfologia das encostas e tabuleiros são também determinantes na expansão para estas regiões hidrográficas.

Geologicamente a área em estudos distribui-se entre as rochas do embasamento, Maciço Pernambuco-Alagoas chamadas de cristalino, (ígneas e metamórficas) distribuídas mais para o interior. $\mathrm{E}$ as rochas da bacia sedimentar costeira que afloram desde Maragogi extremo norte da área até Penedo ao sul. (VILLANUEVA e MARTINS, 2016, p.21)

O Leste Alagoano caracteriza-se por uma ampla faixa junto à linha de costa composta por depósitos marinhos, flúvio-marinhos, flúvio-lagunares, mangues e brejos na planície costeira; pelos tabuleiros costeiros sustentados pelas rochas sedimentares da Formação Barreiras, e por um relevo cristalino de formato colinoso mais para o interior. Com relação aos solos, ocorrem também extensos feixes de cordões arenosos constituídos dominantemente por solos quartzosos, com baixa fertilidade natural e com pequena capacidade de retenção de nutrientes e de umidade. Estes sustentam uma vegetação típica arbustiva/arbórea de restinga próximo à costa. Nos tabuleiros e colinas, dominam solos muito profundos, bastante intemperizados, também de baixa fertilidade natural, friáveis, com textura variando de argilosa a areno-argilosa. Trata-se assim, das áreas originalmente ocupadas por Mata Atlântica.

Quanto aos dados climatológicos do Estado de Alagoas, segundo BARROS et. al. (2012, p.6), no estado não há oscilações importantes na temperatura média do ar, a variação no litoral fica entre $23^{\circ} \mathrm{C}$ e $28^{\circ} \mathrm{C}$. As temperaturas médias do ar ficam mais amenas nas áreas em contato com as encostas do Planalto da Borborema e expostas ao vento Sudeste, que são de altitudes mais elevadas, $\operatorname{com} 21^{\circ} \mathrm{C}$ a $23^{\circ} \mathrm{C}$.

De acordo com a classificação de Köppen, toda a metade oriental do estado possui clima do tipo As', ou seja, tropical e quente com chuvas de outono/ inverno, com precipitação pluviométrica média anual entre $1.000 \mathrm{~mm}$ a $1.500 \mathrm{~mm}$. Porém, parte do leste alagoano, próximo à divisa com o Estado de Pernambuco, possui clima Ams', tropical com chuvas de outono a inverno e médias pluviométricas anuais entre $1.500 \mathrm{~mm}$ a 2.200 mm. (BARROS, A. H. C.; FILHO, J. C. de A.; SILVA, A. B. da; SANTIAGO, G. A. C. F., 2012, p.6). 
A área em estudo faz parte da vergência ${ }^{1}$ ou inclinação atlântica dos rios alagoanos e distribui-se ao longo de nove regiões hidrográficas, sendo 7 de domínio estadual e 2 de domínio federal. As principais bacias hidrográficas e suas áreas são as dos rios: Camaragibe, com 4.087 km2; Mundaú, com 8.021 km2; São Miguel, com 4.132 km2 e parte do rio São Francisco, com 149.046 km2 (PROJETO RADAM, 1983 apud VILLANUEVA, 2016).

\section{FUNDAMENTOS TEÓRICOS}

\section{Organização espacial}

A análise e organização espacial se dão mediante escolhas técnicas e metodológicas, atualizadas e viáveis em suas formulações. Ver o espaço geográfico por um único prisma é limitá-lo. Os métodos empregados para a sua análise devem extrair suas mais diversas faces, incluindo às contraditórias, sem, no entanto, perder de vista sua lógica espaço-temporal. “[...] o espaço geográfico é multidimensional. Aceitar essa multidimensionalidade é aceitar por práticas sociais distintas que, como HARVEY (1973) se refere, permitem construir diferentes conceitos de espaço". (CORRÊA, 2000, p.44)

Um importante elemento de discussão são os discursos sobre o conceito de globalização, em que muitos cientistas chegaram a afirmar que a globalização traria "o fim das regiões pela homogeneização do espaço ou pela uniformização das relações sociais" (LIPIETZ, 1977 apud GOMES, 2000, p.71). Acabam que os movimentos regionais tornam-se de resistência, em defesa das diferenças e contra a insensibilidade às desigualdades. (MARKUSEN, 1981 apud GOMES, 2000, p.71)

Esse regionalismo gerou uma ênfase na ideologia da democracia das minorias e no direito a exclusão, bem como uma oposição entre as noções de comunidade e de cidadão. "Mais uma vez constatamos a relação de proximidade entre território e política, entre limites territoriais de soberania ou autonomia e, mais uma vez, confirmamos a rede de vínculos que estes debates mantêm com o conceito de região”. (GOMES, 2000, p.72)

Segundo Gomes (2000, p.73) apud GURGEL (2018, p.28),

\footnotetext{
${ }^{1}$ Vergência: Sentido ou rumo de deslocamento tectônico de falhas de empurrão e/ou da deformação dos planos axiais em dobras reviradas e que indica o sentido do transporte (relativo ou absoluto) de rochas em faixas orogênicas ou outras tensionadas. (Winge,M., 2020).
} 
[...] os recortes regionais atuais são complexos, múltiplos, mutáveis. O conceito de região possui o fundamento de uma reflexão política de controle e gestão de território, coloca comunidades em questão e realiza a discussão entre autonomia versus poder central.

\section{Modelagem ambiental}

O complexo sistema ambiental se torna compreensível sob a perspectiva da análise geográfica, enquanto disciplina que estuda as organizações espaciais. O desenvolvimento de métodos para modelagem vem sendo abordado constantemente nos últimos anos, impulsionado pelas crescentes necessidades de preservação ambiental diante da produção agrícola de precisão e em larga escala.

Segundo Moreira (1992, p. 113 apud Sánchez, 2013, p.29), impacto ambiental é "qualquer alteração no meio ambiente em um ou mais de seus componentes - provocada por uma ação humana". Com relação à norma internacional ISO 14.001:2004, sobre a qual várias empresas e organizações baseiam seus sistemas de gestão ambiental, o conceito de impacto ambiental adotado é o de "qualquer modificação do meio ambiente, adversa ou benéfica, que resulte, no todo ou em parte, das atividades, produtos ou serviços de uma organização". (SÁNCHEZ, 2013, p.30-31).

Em uma avaliação de impacto são utilizadas diversas técnicas como, por exemplo, a Matriz de Impactos ou Matriz de Causa x Efeito (THOMPSON, 1990) ou Matriz de Leopold (LEOPOLD, CLARK, HANSHAW \& BALSLEY, 1971). A Matriz de Impactos relaciona as características ambientais de um local com os impactos ambientais possíveis de ocorrer com a instalação de um empreendimento. (LEOPOLD, CLARK, HANSHAW \& BALSLEY, 1971)

Ainda não há unanimidade nas definições de risco utilizadas pelos estudiosos da área. Assim, para efeitos práticos na aplicabilidade do estudo, foi selecionada a seguinte definição utilizada pelo Ministério das Cidades, Brasil (2007, p.26), que diz que risco é a "relação entre a possibilidade de ocorrência de um dado processo ou fenômeno, e a magnitude de danos ou consequências sociais e/ou econômicas sobre um dado elemento, grupo ou comunidade. Quanto maior a vulnerabilidade, maior o risco". (BRASIL, 2007, p.26) E, por sua vez, para o mesmo autor, vulnerabilidade é o "grau de perda para um dado elemento, grupo ou comunidade dentro de uma determinada área passível de ser afetada por um fenômeno ou processo". (BRASIL, 2007, p.26) 
Para compor a modelagem ambiental e auxiliar na criação e análise da matriz de impacto, o uso de sistemas de informação geográfica se faz necessário visto que esses "sistemas são de informações a respeito de dados em unidades espacialmente distribuídas, focalizando os fenômenos ocorrentes na superfície terrestre e os seus atributos". (CHRISTOFOLETTI, 1999, p.29)

\section{A formação socioeconômica do estado de Alagoas e o advento da eucaliptocultura}

Dentro do processo histórico de formação do Estado de Alagoas, após a distribuição das sesmarias na ainda parte sul da Capitania de Pernambuco no século XVI, dois elementos produtivos se instalaram e lograram êxito comercial nesta unidade federativa: os primeiros engenhos de açúcar na Zona Litorânea, e as fazendas de gado bovino no interior.

A partir do século XVII é que os engenhos ampliaram para a Zona da Mata e a pecuária para o Sertão. Assim, nesta época, deu-se início a tradição agrícola da monocultura da cana-de-açúcar em Alagoas que perdurou ao longo dos séculos até os dias atuais. "Em 1700, o complexo canavieiro já estava estabilizado em Alagoas e possuía aproximadamente 40 engenhos". (CARVALHO, 2015, p.19)

Os engenhos de açúcar, localizados em sua maioria próximos ao litoral para facilitar e baratear o transporte da carga para o exterior, além da importação de máquinas, utensílios e escravos para o engenho, também se utilizavam bastante dos rios e córregos próximos para consumo humano e, em sua grande parte, para a irrigação canavieira.

Desde os primórdios, assim, vem nossa economia baseada na cultura da cana-de-açúcar, passando por altos e baixos: do apogeu dos engenhos, que marcou o chamado "ciclo do açúcar", de mão-de-obra escrava, às crises que levam à consolidação das usinas. Avançando do litoral aos tabuleiros, a cana-de-açúcar tem, no correr dos tempos, substituído as demais fontes de nossa economia, como o algodão, o feijão, o milho e outras culturas, hoje de pura subsistência, premidas aos aceiros dos canaviais. (BARROS, Tomo I, p.26-27)

Atualmente, o Estado de Alagoas conta com 20 usinas de açúcar e/ou álcool e biocombustível predominantes do litoral e zona da mata alagoana, segundo o Sindicato da Indústria do Açúcar e do Álcool no Estado de Alagoas (2015).

A herança histórica da formação socioeconômica desta época pode ser vista nas relações de dominação de território agrícola ainda hoje quanto à dominação característica de terras dentro do Estado de Alagoas por famílias tradicionais, dentro do sistema 
neoliberal e democrático da república brasileira. O espaço Alagoano tem sua construção marcada pelo latifúndio, a monocultura, a escravidão e o modelo agroexportador.

O papel do estudo das dinâmicas sociais na formação do espaço é, segundo Santos (2012), de grande importância para a compreensão e correta interpretação do mesmo:

Se a Geografia deseja interpretar o espaço humano como o fato histórico que ele é, somente a história da sociedade mundial aliada à sociedade local pode servir como fundamento da compreensão da realidade espacial e permitir a sua transformação a serviço do homem. Pois a História não se escreve fora do espaço e não há sociedade aespacial. O espaço, ele mesmo, é social. (SANTOS, 2012, p.22)

Com o advento da eucaliptocultura em Alagoas em plantio paralelo com a canade-açúcar, vislumbra-se um momento ímpar na formação histórico-econômica do Estado, uma alteração na monocultura da cana-de-açúcar predominante por séculos, explorada desde a redistribuição das sesmarias no ainda território sul da Capitania de Pernambuco.

O eucalipto é uma árvore natural da Austrália e, portanto, exótica para o Brasil, assim como a cana-de-açúcar, tradicional monocultura brasileira. Os plantios de eucalipto existem desde 2002, segundo registros da Secretaria do Desenvolvimento Econômico e Turismo do Estado de Alagoas (ANGEIRAS, 2016), porém eram inexpressivos, apenas a partir de 2013 é que vêm a tornar-se uma atividade econômica expressiva.

Nos parâmetros atuais de divisão social do trabalho, modelo capitalista, vê-se hoje novas formas de domínio pela propriedade privada, transmutada pelos detentores da terra, dos meios de produção e do capital das sesmarias, para os empresários neoliberais de hoje.

Para traduzir os impactos socioambientais atuais, torna-se necessária, além da visão histórica da dominação territorial, a compreensão das relações de trabalho e dominação social no âmbito de estudo da geografia econômica. O modelo capitalista de produção tende a dificultar ainda mais o acesso do pequeno produtor a terra.

O surgimento do sistema capitalista acarretou um aprofundamento da divisão - social assim como geográfica - do trabalho, que separou o homem dos meios de produção; a propriedade destes escapa cada vez mais do produtor direto para se concentrar nas mãos dos detentores do capital. (SANTOS, 2011, p.138)

É neste contexto histórico-geográfico e social que se faz pertinente a análise dos impactos econômicos e ambientais na Mesorregião do Leste Alagoano, no intuito de capturar defasagens de planejamento que desencadeiem inconsistências em uma nova 
exploração de mercado e no cumprimento dos direitos sociais dos envolvidos direta e indiretamente. As perspectivas de crescimento efetivo no Estado necessitam da comunhão da evolução do poder econômico com o funcionamento das políticas públicas e socioambientais.

\section{METODOLOGIA}

Para o desenvolvimento deste trabalho foram utilizados dados bibliográficos sobre o Estado, históricos, pertinentes a sua formação econômica, espaciais, referentes a sua formação e divisão territorial. (Figura 3)

FIGURA 3 - Organograma de etapas metodológicas

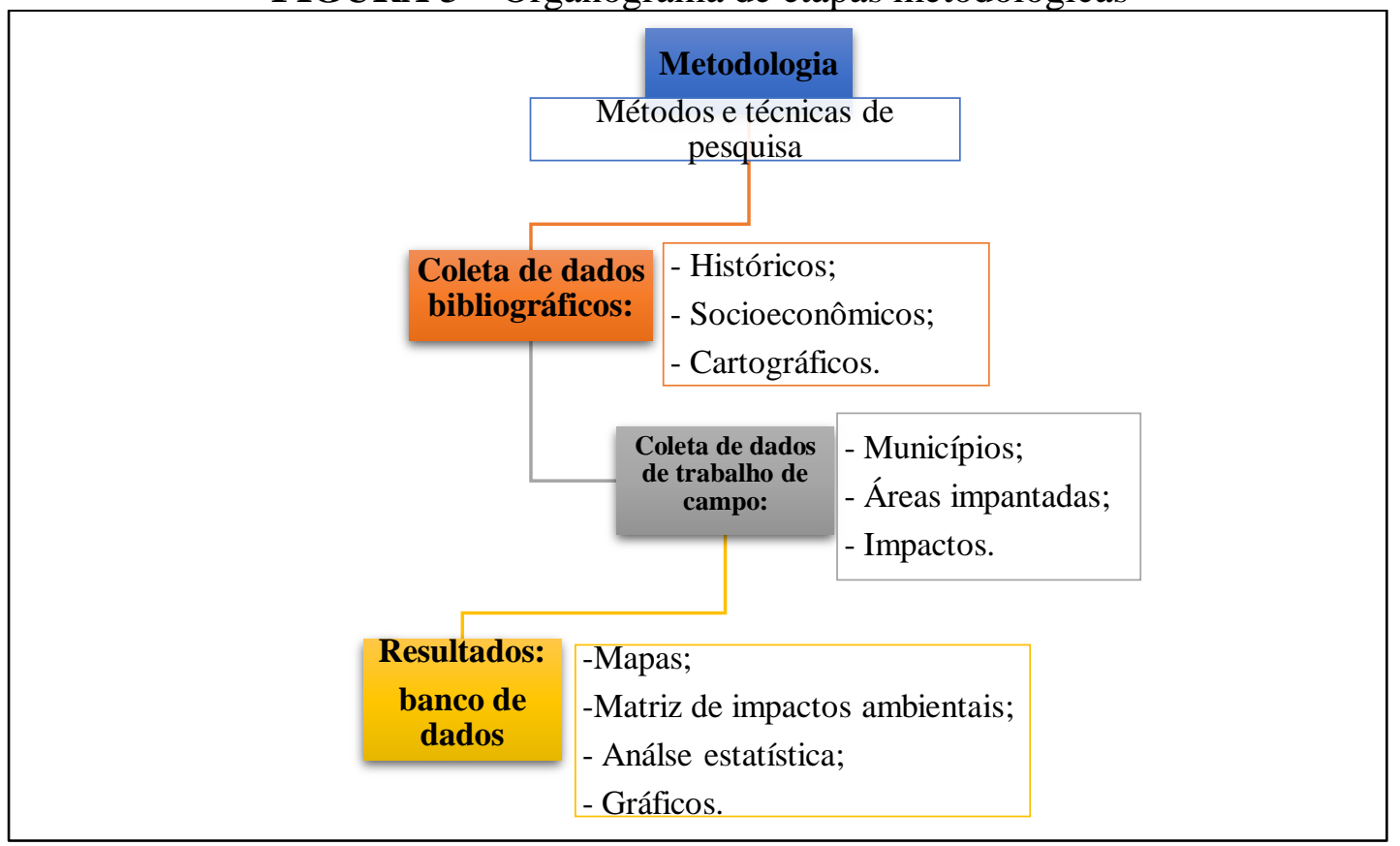

Fonte: Elaborado pelas autoras.

Tais dados bibliográficos foram confrontados com os dados coletados em campo nas condições, critérios e abrangência das modificações advindas do plantio do eucalipto nos municípios. Além disso, também foram levantados dados institucionais da gestão estadual e regional envolvidos no processo da cadeia produtiva do agronegócio do eucalipto.

A partir dos levantamentos iniciais, foi criado um banco de dados histórico e espacial e construída a espacialização digital das alterações por meio de cartografia temática digital e geoprocessamento. Para tal construção, se fez necessária a utilização de 
programas (softwares) auxiliares como editor de planilhas e gráficos, e específico para geoprocessamento e cartografia, como QGIS.

Conforme o banco de dados cartográfico foi sendo construído, a análise comparativa dos dados pôde ser iniciada apresentando as modificações por período, bem como a redação, reflexões e análises, mostrando o panorama integrado dos setores econômico, social e ambiental da região.

Assim, para a modelagem dos impactos ambientais, e integração das características físico-geográficas utilizamos a Matriz de Leopold (1971), a qual integra os principais riscos e situações possíveis nas fases de implantação, operação e utilização do plantio dos eucaliptos, associados aos fatores ambientais e socioeconômicos.

\section{RESULTADOS E DISCUSSÕES}

\section{Análise socioeconômica}

Com as informações levantadas, foi possível a correlação os dados e ofertar um panorama do status de desenvolvimento regional e local em um período de quinze anos (2002 a 2016), essa escolha deve-se a 2002 ser o ano em que se iniciou o plantio de eucalipto no Estado, segundo a Secretaria de Desenvolvimento Econômico e Turismo do Estado de Alagoas (SEDETUR-AL). Como o ano corrente desta análise é 2018, utilizamos 2016 como o limite para integralização dos dados no trabalho.

Para se ter uma ideia preliminar da importância da mesorregião para o Estado de Alagoas, e a implantação da eucaliptocultura, seguem alguns dados que demonstram o panorama atual da área e sua dinâmica socioeconômica. (Quadro 2) 
QUADRO 2 - Situação socioeconômica da Mesorregião do Leste de Alagoas e suas relações com a cultura do eucalipto

\begin{tabular}{|c|c|c|}
\hline \multicolumn{3}{|c|}{$\begin{array}{l}\text { SITUAÇÃO SOCIOECONÔMICA DA MESORREGIÃO LESTE DO ESTADO DE ALAGOAS E SUAS } \\
\text { RELAÇÕES COM A CULTURA DO EUCALIPTO }\end{array}$} \\
\hline Variáveis & Mesorregião Leste & Alagoas \\
\hline Quantidade de municípios 2010 & 52 & 102 \\
\hline Área $\left(\mathrm{km}^{2}\right) 2010$ & $13.292,76$ & $27.848,158$ \\
\hline População total 2010 & 2.064 .525 & 3.120 .494 \\
\hline Densidade demográfica (hab./km²) 2010 & 155,31 & 112,33 \\
\hline Produto Interno Bruto (PIB) per capita 2014 & $\mathrm{R} \$ 10.702,78$ & $\mathrm{R} \$ 12.335,44$ \\
\hline Índice de Desenvolvimento Humano Municipal (IDH-M) 2010 & 0,577 & 0,631 \\
\hline Índice de Gini (distribuição de renda) 2010 & 0,51 & 0,63 \\
\hline Índice de Vulnerabilidade Social (IVS) 2010 & 0,514 & 0,461 \\
\hline Quantidade de usinas de açúcar 2017 & 20 & 20 \\
\hline Quantidade de destilarias 2017 & 16 & 16 \\
\hline Quantidade de municípios com plantio de cana-de-açúcar & 49 & 54 \\
\hline Quantidade de cerâmicas 2017 & 18 & 23 \\
\hline Quantidade de cerâmicas que plantam e consomem eucalipto 2017 & 7 & 7 \\
\hline Quantidade de cerâmicas que compram eucalipto para consumo 2017 & 3 & 6 \\
\hline Quantidade de plantadores de eucalipto até 2016 & 51 & 58 \\
\hline Quantidade de municípios com plantio de eucalipto 2016 & 33 & 38 \\
\hline Quantidade de hectares plantados com eucalipto 2016 & $10.956,2$ & $11.013,7$ \\
\hline
\end{tabular}

Fonte: Elaborado pelas autoras. Dados: Censo IBGE, 2010. IPEA, 2017. PNUD - Atlas de Desenvolvimento Humano, 2017. SINDAÇÚCAR, 2017. SINDICER, 2017. SEDETUR, 2016.

Pode-se observar, de acordo com os dados acima, que a Mesorregião do Leste Alagoano é a de maior peso socioeconômico para o estado, visto que contém mais da metade dos municípios do estado, quase metade da área total do estado e concentra a parcela de recursos naturais com condições de maior disputa de investimento financeiro devido sua alta produtividade consequente de suas características edafoclimáticas. Nesse sentido, o cultivo do eucalipto só soma aos interesses existentes nessa parcela do estado de Alagoas.

\section{Análise ambiental}

Por meio da utilização de uma matriz de interação de impactos ambientais e fatores socioeconômicos, e com base na Matriz de Leopold (1971), foi montada a matriz adaptada à situação de plantio de eucalipto. Assim, foi obtido um resultado do quadro panorâmico, com o status de cada variável com a ação ou o processamento das etapas do plantio de eucalipto. 
Dessa forma, foram avaliados os impactos ambientais nas várias etapas: implantação (supressão da vegetação; plantio inicial; edificações, sistemas viários e infraestrutura; canteiro de obras; desmobilização do canteiro de obras), operação (esgotamento sanitário; coleta e disposição de resíduos sólidos; operação do projeto; uso de formicidas e herbicidas) e utilização (termelétrica e biomassa; indústria moveleira e de pallets; arquitetura e decoração); bem como sua relação com fatores dos meios: físico (solo, topografia, recursos hídricos), biótico (flora e fauna) e antrópico (geração de renda e aspectos paisagísticos). Foram identificados e atribuídos valores aos impactos ambientais e socioeconômicos de acordo com a interação com cada etapa ou ação proposta, bem como com cada fator físico, biótico e antrópico (Quadro 3).

QUADRO 3 - Descrição das variáveis

\begin{tabular}{|l|}
\hline Risco de erosão. \\
\hline Risco de impermeabilidade. \\
\hline Risco de contaminação. \\
\hline Risco de assoreamento. \\
\hline Risco de escoamento superficial. \\
\hline Risco de redução do nível da água. \\
\hline Risco de contaminação por resíduos sólidos. \\
\hline Risco de voçoroca. \\
\hline Alteração da paisagem natural. \\
\hline Perda de biomassa natural e diminuição da biodiversidade. \\
\hline Risco de colonização de espécies invasoras. \\
\hline Risco de acidentes com animais peçonhentos. \\
\hline Perda de habitat, nichos, fontes de alimentação, áreas de nidificação e pouso. \\
\hline Perda de indivíduos, alteração na migração e afugentamento. \\
\hline Redução ou perda de espécies nativas controladoras de pragas. \\
\hline Risco de contratação de mão de obra especializada de fora do estado. \\
\hline
\end{tabular}

Fonte: Adaptado de CUNHA NETA, 2011; LIMA, 2017.

Assim, a relação entre as etapas e ações de acordo com as características pesquisadas podem ser vistas no quadro 4 . 
Revista de Geografia (Recife) V. 37, No. 1, 2020

QUADRO 4 - Matriz de interação de impactos MATRIZ DE INTERAÇÃO DE IMPACTOS

\begin{tabular}{|c|c|c|c|c|c|c|c|c|c|c|c|c|c|}
\hline \multicolumn{14}{|c|}{ MATRIZ DE INTERAÇÃO DE IMPACTOS } \\
\hline \multirow{3}{*}{\multicolumn{2}{|c|}{$\begin{array}{c}\text { Fatores ambientais / } \\
\text { Fatores } \\
\text { socioeconômicos }\end{array}$}} & \multicolumn{12}{|c|}{ ETAPAS E AÇÕES } \\
\hline & & \multicolumn{5}{|c|}{ Implantação } & \multicolumn{4}{|c|}{ Operação } & \multicolumn{3}{|c|}{ Utilização } \\
\hline & & Supressão da & Plantio inicial & $\begin{array}{c}\text { Edificações, } \\
\text { sistemas viários e }\end{array}$ & Canteiro de & $\begin{array}{l}\text { Desmobilização } \\
\text { do canteiro de }\end{array}$ & Esgotamento & $\begin{array}{c}\text { Coleta e } \\
\text { destinação de }\end{array}$ & Operação do & $\begin{array}{c}\text { Uso de } \\
\text { formicidas e }\end{array}$ & $\begin{array}{c}\text { Termelétrica / } \\
\text { Biomassa: }\end{array}$ & $\begin{array}{l}\text { Indústria } \\
\text { moveleira e }\end{array}$ & Arquitetura e \\
\hline \multirow{3}{*}{ 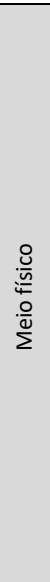 } & Solos & $\begin{array}{l}\text { Risco de erosão } \\
\text { Risco de } \\
\text { escoamento } \\
\text { superficial }\end{array}$ & - & $\begin{array}{c}\text { Risco de } \\
\text { impermeabilização }\end{array}$ & $\begin{array}{c}\text { Risco de } \\
\text { contaminação }\end{array}$ & - & $\begin{array}{c}\text { Risco de } \\
\text { contaminação }\end{array}$ & $\begin{array}{c}\text { Risco de } \\
\text { contaminação }\end{array}$ & $\begin{array}{c}\text { Risco de } \\
\text { escoamento } \\
\text { superficial }\end{array}$ & $\begin{array}{c}\text { Risco de } \\
\text { contaminação }\end{array}$ & $\begin{array}{c}\text { Risco de } \\
\text { contaminação } \\
\text { por resíduos } \\
\text { sólidos }\end{array}$ & $\begin{array}{c}\text { Risco de } \\
\text { contaminação } \\
\text { por resíduos } \\
\text { sólidos }\end{array}$ & $\begin{array}{c}\text { Risco de } \\
\text { contaminação } \\
\text { por resíduos } \\
\text { sólidos }\end{array}$ \\
\hline & $\begin{array}{l}\text { Topografia } \\
\text { Encosta / } \\
\text { Tabuleiro }\end{array}$ & $\begin{array}{l}\text { Risco de erosão } \\
\text { Risco de } \\
\text { escoamento } \\
\text { superficial }\end{array}$ & $\begin{array}{l}\text { Risco de } \\
\text { voçoroca }\end{array}$ & $\begin{array}{c}\text { Risco de } \\
\text { escoamento } \\
\text { superficial }\end{array}$ & $\begin{array}{c}\text { Risco de } \\
\text { escoamento } \\
\text { superficial }\end{array}$ & $\begin{array}{c}\text { Risco de } \\
\text { escoamento } \\
\text { superficial }\end{array}$ & - & - & $\begin{array}{c}\text { Risco de } \\
\text { escoamento } \\
\text { superficial }\end{array}$ & - & - & - & - \\
\hline & $\begin{array}{l}\text { Recursos } \\
\text { Hídricos }\end{array}$ & $\begin{array}{l}\text { Risco de } \\
\text { assoreamento } \\
\text { Risco de } \\
\text { diminuição do } \\
\text { nível da água }\end{array}$ & $\begin{array}{l}\text { Risco de } \\
\text { voçoroca }\end{array}$ & $\begin{array}{c}\text { Risco de } \\
\text { diminuição do nível } \\
\text { da água }\end{array}$ & $\begin{array}{c}\text { Risco de } \\
\text { contaminação }\end{array}$ & - & $\begin{array}{c}\text { Risco de } \\
\text { contaminação }\end{array}$ & $\begin{array}{c}\text { Risco de } \\
\text { contaminação }\end{array}$ & $\begin{array}{c}\text { Risco de } \\
\text { contaminação }\end{array}$ & $\begin{array}{c}\text { Risco de } \\
\text { contaminação }\end{array}$ & $\begin{array}{c}\text { Risco de } \\
\text { contaminação }\end{array}$ & $\begin{array}{c}\text { Risco de } \\
\text { contaminação }\end{array}$ & - \\
\hline \multirow[b]{2}{*}{ 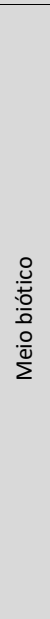 } & Flora & $\begin{array}{c}\text { Perda de } \\
\text { biomassa } \\
\text { natural e } \\
\text { diminuição da } \\
\text { biodiversidade }\end{array}$ & $\begin{array}{c}\text { Perda de } \\
\text { biomassa } \\
\text { natural e } \\
\text { diminuição da } \\
\text { biodiversidade }\end{array}$ & $\begin{array}{c}\text { Perda de biomassa } \\
\text { natural e } \\
\text { diminuição da } \\
\text { biodiversidade }\end{array}$ & $\begin{array}{c}\text { Perda de } \\
\text { biomassa } \\
\text { natural e } \\
\text { diminuição da } \\
\text { biodiversidade }\end{array}$ & $\begin{array}{l}\text { Risco de } \\
\text { colonização de } \\
\text { espécies } \\
\text { invasoras }\end{array}$ & - & - & - & - & - & - & - \\
\hline & Fauna & $\begin{array}{c}\text { Perda de } \\
\text { habitat, nichos, } \\
\text { fontes de } \\
\text { alimentação, } \\
\text { áreas de } \\
\text { nidificação e } \\
\text { pouso } \\
\text { Perda de } \\
\text { indivíduos, }\end{array}$ & $\begin{array}{c}\text { Perda de } \\
\text { habitat, nichos, } \\
\text { fontes de } \\
\text { alimentação, } \\
\text { áreas de } \\
\text { nidificação e } \\
\text { pouso } \\
\text { Perda de } \\
\text { indivíduos, }\end{array}$ & $\begin{array}{l}\text { Perda de habitat, } \\
\text { nichos, fontes de } \\
\text { alimentação, áreas } \\
\text { de nidificação e } \\
\text { pouso } \\
\text { Perda de } \\
\text { indivíduos, } \\
\text { alteração na }\end{array}$ & $\begin{array}{c}\text { Perda de } \\
\text { habitat, nichos, } \\
\text { fontes de } \\
\text { alimentação, } \\
\text { áreas de } \\
\text { nidificação e } \\
\text { pouso } \\
\text { Perda de } \\
\text { indivíduos, }\end{array}$ & - & - & - & $\begin{array}{c}\text { Risco de } \\
\text { acidentes com } \\
\text { animais } \\
\text { peçonhentos } \\
\text { Perda de } \\
\text { indivíduos, } \\
\text { alteração na } \\
\text { migração e } \\
\text { afugentamento }\end{array}$ & $\begin{array}{c}\text { Redução ou } \\
\text { perda de } \\
\text { espécies } \\
\text { nativas } \\
\text { controladoras } \\
\text { de pragas }\end{array}$ & $\begin{array}{c}\text { Perda de } \\
\text { habitat, nichos, } \\
\text { fontes de } \\
\text { alimentação, } \\
\text { áreas de } \\
\text { nidificação e } \\
\text { pouso } \\
\text { Perda de } \\
\text { indivíduos, }\end{array}$ & $\begin{array}{c}\text { Perda de } \\
\text { habitat, nichos, } \\
\text { fontes de } \\
\text { alimentação, } \\
\text { áreas de } \\
\text { nidificação e } \\
\text { pouso } \\
\text { Perda de } \\
\text { indivíduos, }\end{array}$ & - \\
\hline
\end{tabular}


Revista de Geografia (Recife) V. 37, No. 1, 2020

\begin{tabular}{|c|c|c|c|c|c|c|c|c|c|c|c|c|}
\hline & & $\begin{array}{l}\text { alteração na } \\
\text { migração e } \\
\text { afugentamento }\end{array}$ & $\begin{array}{l}\text { alteração na } \\
\text { migração e } \\
\text { afugentamento }\end{array}$ & $\begin{array}{c}\text { migração e } \\
\text { afugentamento }\end{array}$ & $\begin{array}{l}\text { alteração na } \\
\text { migração e } \\
\text { afugentamento }\end{array}$ & & & & & $\begin{array}{l}\text { alteração na } \\
\text { migração e } \\
\text { afugentamento }\end{array}$ & $\begin{array}{l}\text { alteração na } \\
\text { migração e } \\
\text { afugentamento }\end{array}$ & \\
\hline \multirow[t]{2}{*}{ 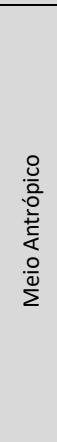 } & $\begin{array}{l}\text { Contratação } \\
\text { de mão de } \\
\text { obra/renda }\end{array}$ & $\begin{array}{l}\text { Risco de } \\
\text { acidentes com } \\
\text { animais } \\
\text { peçonhentos }\end{array}$ & $\begin{array}{l}\text { Risco de } \\
\text { contratação de } \\
\text { mão de obra } \\
\text { especializada de } \\
\text { fora do estado }\end{array}$ & - & - & $\begin{array}{c}\text { Risco de } \\
\text { contratação } \\
\text { de mão de } \\
\text { obra } \\
\text { especializada } \\
\text { de fora do } \\
\text { estado }\end{array}$ & $\begin{array}{c}\text { Risco de } \\
\text { contratação } \\
\text { de mão de } \\
\text { obra } \\
\text { especializada } \\
\text { de fora do } \\
\text { estado }\end{array}$ & $\begin{array}{c}\text { Risco de } \\
\text { contratação de } \\
\text { mão de obra } \\
\text { especializada de } \\
\text { fora do estado }\end{array}$ & $\begin{array}{c}\text { Risco de } \\
\text { contratação } \\
\text { de mão de } \\
\text { obra } \\
\text { especializada } \\
\text { de fora do } \\
\text { estado }\end{array}$ & $\begin{array}{l}\text { Risco de } \\
\text { contratação de } \\
\text { mão de obra } \\
\text { especializada de } \\
\text { fora do estado }\end{array}$ & - & - \\
\hline & $\begin{array}{c}\text { Aspectos } \\
\text { paisagísticos }\end{array}$ & $\begin{array}{c}\text { Alteração da } \\
\text { paisagem } \\
\text { natural }\end{array}$ & $\begin{array}{c}\text { Alteração da } \\
\text { paisagem } \\
\text { natural }\end{array}$ & $\begin{array}{c}\text { Alteração da } \\
\text { paisagem natural }\end{array}$ & $\begin{array}{c}\text { Alteração da } \\
\text { paisagem } \\
\text { natural }\end{array}$ & $\begin{array}{c}\text { Alteração da } \\
\text { paisagem } \\
\text { natural }\end{array}$ & $\begin{array}{c}\text { Alteração da } \\
\text { paisagem } \\
\text { natural }\end{array}$ & $\begin{array}{c}\text { Alteração da } \\
\text { paisagem } \\
\text { natural }\end{array}$ & $\begin{array}{c}\text { Alteração da } \\
\text { paisagem } \\
\text { natural }\end{array}$ & $\begin{array}{c}\text { Alteração da } \\
\text { paisagem } \\
\text { natural }\end{array}$ & $\begin{array}{c}\text { Alteração da } \\
\text { paisagem } \\
\text { natural }\end{array}$ & $\begin{array}{c}\text { Alteração da } \\
\text { paisagem } \\
\text { natural }\end{array}$ \\
\hline
\end{tabular}

Fonte: Adaptado de CUNHA NETA, 2011; LIMA, 2017. 
Os valores dos impactos ambientais foram avaliados quanto ao tipo e a intensidade dos mesmos, de acordo com o quadro 5.

QUADRO 5 - Valores para avaliação de impacto

\begin{tabular}{|l|c|c|c|}
\hline Tipo de impacto & Nulo (N) & Positivo (+) & Negativo (-) \\
\hline Intensidade do impacto & Alta (A) & Média (M) & Baixa (B) \\
\hline
\end{tabular}

Fonte: Adaptado de LIMA, 2017.

Assim, de posse dos impactos ambientais, foi possível a criação de um quadro de valoração dos impactos ambientais versus a interação de suas variáveis (Quadro 6).

QUADRO 6 - Matriz de valoração de impactos

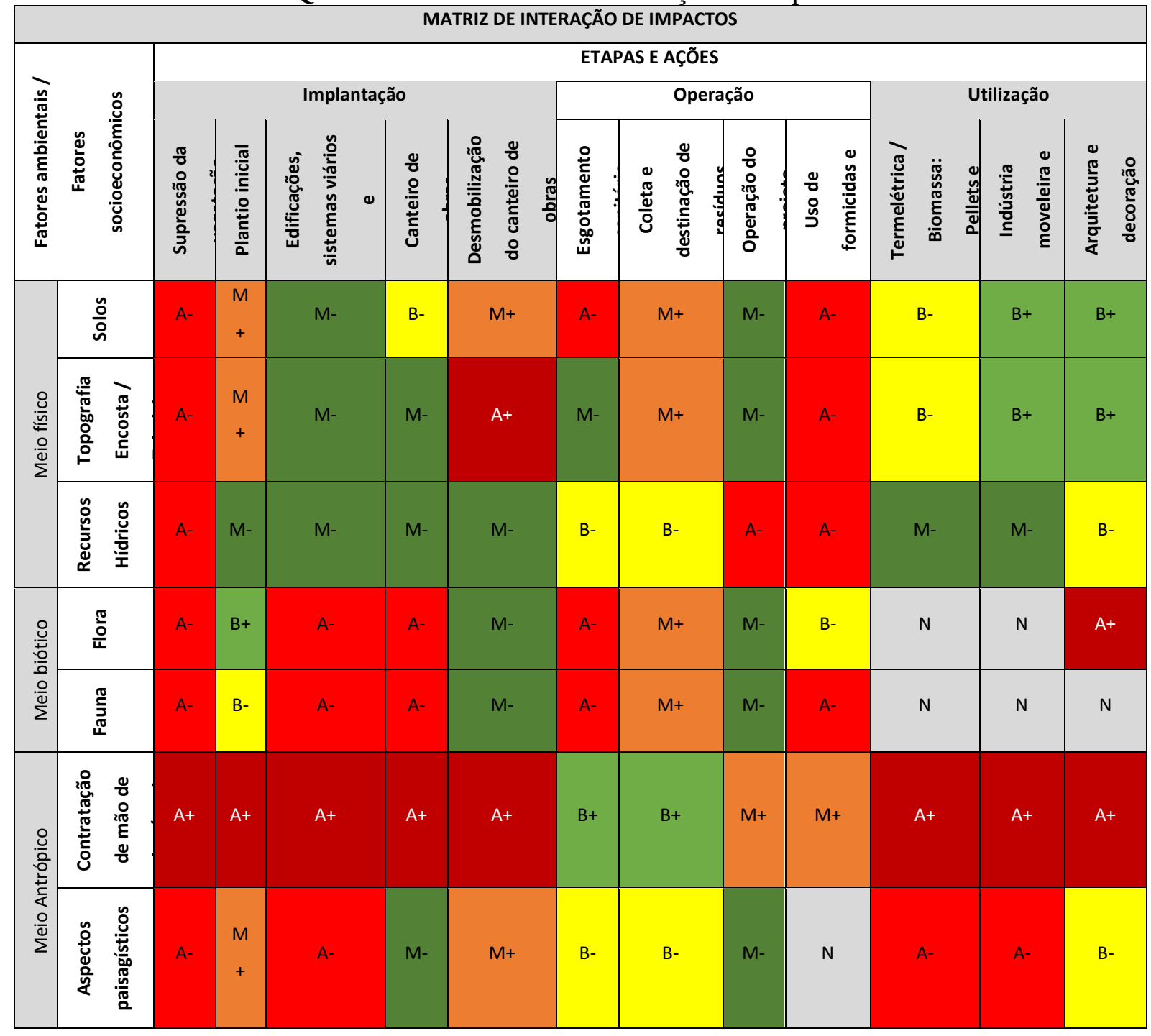

Fonte: Adaptado de CUNHA NETA, 2011; LIMA, 2017. 


Valores dos impactos:
\begin{tabular}{|l|l|}
\hline A + & Alto positivo \\
\hline A - & Alto negativo \\
\hline M + & Médio positivo \\
\hline M - & Médio negativo \\
\hline B + & Baixo positivo \\
\hline B - & Baixo negativo \\
\hline N & Nulo \\
\hline
\end{tabular}

Com a análise da matriz de impactos e os valores atribuídos às possibilidades de alteração em cada etapa, percebeu-se a geração de uma diversidade de impactos positivos e negativos de intensidades diferenciadas. Vale-se ressaltar que computamos valores nulos para aquelas interações entre etapas e fatores as quais não foram identificadas alterações.

Nos resultados de porcentagem de impactos pode-se perceber que em um total de 84 alterações identificadas na matriz, destacam-se os impactos: alto negativo (A-) com 25\% dos casos; médios negativos (M-) com 22\%; médios positivos $(\mathrm{M}+)$ e baixo negativos (B-) ambos com 13\%; alto positivos (A+) com 12\%; baixo positivos (B+) com 8\% e os impactos nulos ou ausências de alterações com 7\% (Gráfico 1).

GRÁFICO 1 - Porcentagem de impactos para a eucaliptocultura em Alagoas

\section{Porcentagem de impacto por valor}
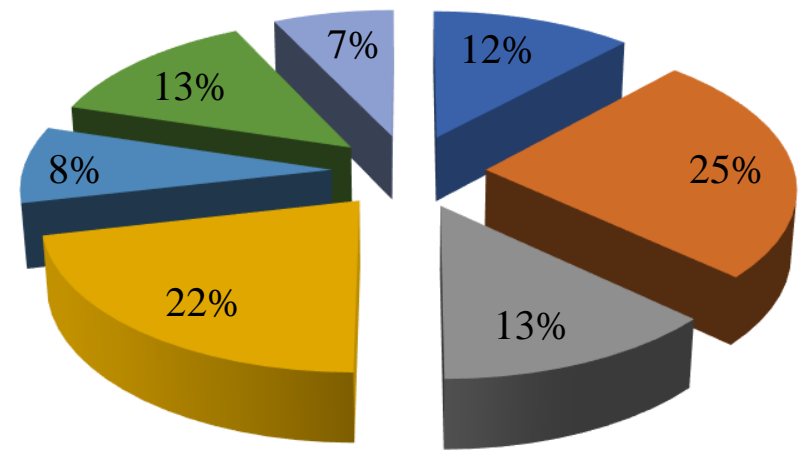

- Alto Positivo(A+)

- Alto Negativo (A-)

Médio Positivo (M+)

Médio Negativo (M-)

- Baixo Positivo (B+)

Baixo Negativo (B-)

Nulo (N)

Fonte: Elaborado pelas autoras a partir da matriz de valoração de impactos, Quadro 6. 
Avaliando-se o gráfico acima (Gráfico 1), pode-se perceber que os impactos gerados na implantação, operação e utilização apresentam um saldo de impactos negativos sobre os positivos.

Quanto ao tipo de impacto, positivo ou negativo, a alterações demonstraram ter maior peso negativo, totalizando $60 \%$ ou 50 aparições na matriz, em relação a um positivo de $33 \%$ ou 28 surgimentos na matriz e um nulo de $7 \%$ ou 6 ausências de impacto. Somando os impactos positivos aos nulos, pela característica comum de não produzirem um resultado ruim, então teremos $40 \%$ de impactos positivos (positivo + nulo) e $60 \%$ impactos negativos (Gráfico 2).

GRÁFICO 2 - Porcentagem de impacto por tipo para a eucaliptocultura em Alagoas

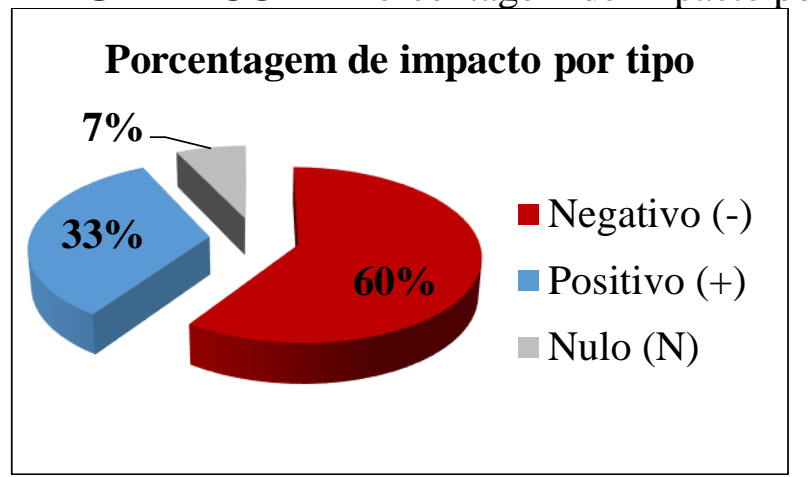

\section{Porcentagem de impacto por tipo}

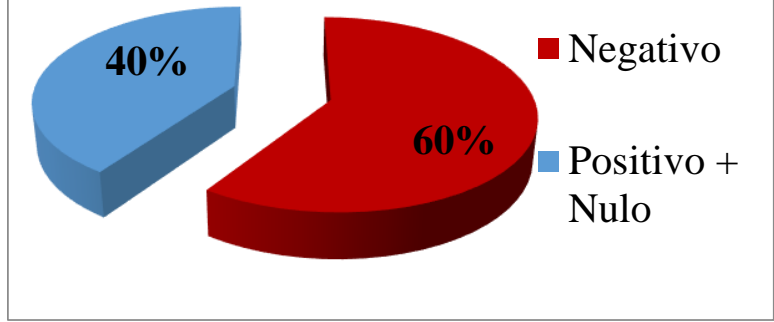

Fonte: Elaborado pelo autor a partir da matriz de valoração de impactos, Quadro 15.

Dessa forma, conclui-se que o cultivo de eucalipto em paralelo com a cana-deaçúcar, em áreas que antes eram apenas deste último cultivo, não se configura como novo advento socioeconômico e ambiental que traga benefícios para as esferas públicas e civis, apenas para a privada. Ainda sim, a esfera privada necessitará realizar a aplicação de medidas mitigatórias para o alto e médio impacto negativo que se configura com as possibilidades elencadas nessa pesquisa, para que a partir daí seja um cultivo de melhor aproveitamento socioambiental. 
O cultivo da cana-de-açúcar, por sua vez, também apresenta impactos negativos similares, os quais têm sido reduzidos através de algumas medidas mitigadoras, tais como a diminuição das queimadas e o uso da vinhaça na fertirrigação².

\section{CONSIDERAÇÕES FINAIS}

O cultivo do eucalipto em Alagoas em paralelo com a cana-de-açúcar não pode ser dissociado à formação histórica e socioeconômica do Estado, figurando como importante alteração na forma de ocupação, distribuição e modo de vida, marcada pela vocação secular da monocultura canavieira. Agora, com a baixa dos preços da cana-deaçúcar e seus derivados no Brasil, surge a oportunidade da implantação de outras culturas, como o eucalipto.

A Mesorregião do Leste Alagoano por ser a de maior valoração econômica do Estado, conter aproximadamente metade da área do estado e dos municípios alagoanos, alta produtividade e características edafoclimáticas e melhores condições de mobilidade, foi escolhida para a implantação da eucaliptocultura.

Assim, o cultivo do eucalipto vem ocupando áreas de encostas propensas à regeneração da Mata Atlântica levando aos riscos de erosão, assoreamento, diminuição do escoamento superficial, redução do nível da água, perda de habitat, entre outros.

Esses fatores podem alterar rios na sua quantidade e qualidade, pelo aporte de sedimentos. Além do mais, as áreas próximas aos rios, as Áreas de Proteção Permanente - APPs, são ambientes especiais e já protegidos por leis.

Com a modelagem dos impactos ambientais causados com a implantação da eucaliptocultura não se tem uma alteração tão positiva no ambiente, mesmo já ocorrendo em uma área já antropizada pelo cultivo da cana-de-açúcar. Pode-se perceber a interrelação dos diversos ecossistemas e que economicamente para a Mesorregião também não se configura como uma alteração estrutural, socioeconômica e ambiental voltada a

\footnotetext{
${ }^{2}$ Fertirrigação é uma técnica de aplicação simultânea de fertilizantes e água, através de um sistema de irrigação. (EMBRAPA, 2019)
} 
interesses públicos e comuns. Ou seja, pode se tornar a reprodução do quadro socioeconômico gerado pela cana.

\section{REFERÊNCIAS}

ANGEIRAS, G. J. de S. L. Mapear a implantação de florestas energéticas em Alagoas. SEDETUR - Secretaria do Desenvolvimento Econômico e Turismo. Estado de Alagoas: Maceió, 2016.

BARros, A. H. C.; FilHO, J. C. de A.; SIlva, A. B. da; SANTIAGO, G. A. C. F. Climatologia do estado de Alagoas. Boletim de pesquisa e desenvolvimento 211. Recife: EMBRAPA Solos, dez. 2012. Disponível em: https://www.embrapa.br/solos/busca-de-publicacoes/-/publicacao/950797/climatologiado-estado-de-alagoas. Acesso em: 10 dez. 2019.

BARROS, F. R. A. de. ABC das Alagoas: dicionário bibliográfico, histórico e geográfico das Alagoas. Tomo I. Brasília: Senado Federal, Conselho Editorial, 2005.

BRASIL. CARVALHO, C. S.; MACEDO, E. S. de; OGURA, A. T. (Org.) Mapeamento de Riscos em Encostas e Margem de Rios. Brasília: Ministério das Cidades; Instituto de Pesquisas Tecnológicas - IPT, 2007. 176 p.

CARVALHO, C. P. de. Formação histórica de Alagoas. 3. ed. rev. e ampl. EDUFAL: Maceió, 2015.

CORRÊA, R. L. Espaço: um conceito-chave da geografia. In: CASTRO, I. E. de C.; GOMES, P. C. da C.; CORRÊA, R. L. (Orgs.) Geografia: conceitos e temas. 2.ed. Rio de Janeiro: Bertrand Brasil, 2000. p.15-47.

CUNHA NETA, A. M. de M. Modelagem de impactos ambientais causados pela monocultura do eucalipto. In: XV Simpósio Brasileiro de Sensoriamento Remoto SBSR, 30 de abril a 05 de maio de 2011, Curitiba. Anais eletrônicos... Curitiba: INPE, 2011. Disponível em: http://www.dsr.inpe.br/sbsr2011/files/p0300.pdf. Acesso em: 16 mai. 2017.

EMBRAPA. Manejo da fertirrigação. Agência de Informação Embrapa Manga. MAPA. Disponível em: 
https://www.agencia.cnptia.embrapa.br/Agencia22/AG01/arvore/AG01_53_241120051 15222.html. Acesso em: $10 \mathrm{dez} .2019$.

GOMES, P. C. C. O conceito de região e sua discussão. In: CASTRO, I. E. de C.; GOMES, P. C. C.; CORRÊA, R. L. (Orgs.) Geografia: conceitos e temas. 2.ed. Rio de Janeiro: Bertrand Brasil, 2000. p.49-76.

GURGEL, V. A. Transformações nas dinâmicas espaciais no estado de Alagoas com inserção da eucaliptocultura na mesorregião geográfica do leste alagoano. 2018. 101 f. Dissertação. (Pós-Graduação em Geografia - Área de concentração Organização do espaço geográfico) - Instituto de Geografia, Desenvolvimento e Meio Ambiente. Universidade Federal de Alagoas, Maceió, 2018.

LEOPOLD, L. B.; CLARK, F. E.; HANSHAW, B. B.; BALSLEY, J. R. A procedure for evaluating environmental impact. Geological Survey Circular 645, United States

Department of the Interior. Washington, D.C., 1971.

LIMA, M. C. S. Recuperação de áreas de manguezais degradados por aterramento, estudo de caso no Litoral Norte de Maceió-AL. 2017. 74 f. Trabalhos de Conclusão de Curso (Curso de Engenharia Ambiental e Sanitária) - Centro de Tecnologia (CTEC), Universidade Federal de Alagoas, Maceió, 2017.

SÁNCHEZ, L. E. Avaliação de Impacto Ambiental: conceitos e métodos. 2 ed. São Paulo:

Oficina de Textos, 2013.

SANTOS, Milton. Da totalidade ao lugar. 1 ed. 2 reimpr. EDUSP: São Paulo, 2012.

SANTOS, Milton. Economia Espacial: Críticas e Alternativas. 2 ed. $2^{\mathrm{a}}$ reimpr. EDUSP: São Paulo, 2011.

SINDAÇÚCAR - Sindicato da Indústria do Açúcar do Álcool no Estado de Alagoas.

Relação das usinas. Disponível em: http://www.sindacucar-al.com.br/relacao-dasusinas/. Acesso em: 03 nov. 2017.

STF - Supremo Tribunal Federal. Queimadas em canaviais: bibliografia, legislação e jurisprudência temática. Secretaria de documentação. Coordenadoria de Biblioteca. Biblioteca Ministro Victor Nunes Leal, 2013. 
VILlANUEVA, T. C. B.; MARTINS, V.de S. (Org.) Geodiversidade do Estado de Alagoas. Programa Geologia do Brasil. Levantamento da Geodiversidade. Ministério de Minas e Energia. Salvador: CPRM, 2016.

WINGE, M. et. al. 2001 - 2020. Vergência. Glossário Geológico Ilustrado. Disponível em: http://sigep.cprm.gov.br/glossario/. Acesso em: 10 dez. 2019. 